\title{
Three-dimensional printing to facilitate anatomic study, device development, simulation, and planning in thoracic surgery
}

\author{
Sergei N. Kurenov, MS, ${ }^{a}$ Ciprian Ionita, PhD, ${ }^{b}$ Dan Sammons, ${ }^{c}$ and Todd L. Demmy, MD
}

\section{ABSTRACT}

Background: The development and deployment of new technologies in additive 3-dimensional (3D) printing (ie, rapid prototyping and additive manufacturing) in conjunction with medical imaging techniques allow the creation of anatomic models based on patient data.

Objective: To explore this rapidly evolving technology for possible use in care and research for patients undergoing thoracic surgery.

Methods: Because of an active research project at our institution on regional lung chemotherapy, human pulmonary arteries (PAs) were chosen for this rapid prototyping project. Computed tomography (CT) and CT angiography in combination with segmentation techniques from 2 software packages were used for rapid generation and adjustment of the 3D polygon mesh and models reconstruction of the PAs. The reconstructed models were exported as stereolithographic data sets and further processed by trimming, smoothing, and wall extrusion.

Results: Flexible 3D printed replicas of 10 patient PAs were created successfully with no print failures; however, 1 initial test print with a $1 \mathrm{~mm}$ mural thickness was too fragile so the whole group was printed with a $1.5 \mathrm{~mm}$ wall. The design process took 8 hours for each model (CT image to stereolithographic) and printing required 97 hours in aggregate. Useful differences in anatomy were defined by this method, such as the expected greater number of proximal branches on the left versus right $(2.5 \pm 1.1$ vs $1.0 \pm 0.0 ; P=.001)$.

Conclusions: Reconstructed models of pulmonary arteries using 3D rapid prototyping allow replication of sophisticated anatomical structures that can be used to facilitate anatomic study, surgical planning, and device development. (J Thorac Cardiovasc Surg 2015;149:973-9)

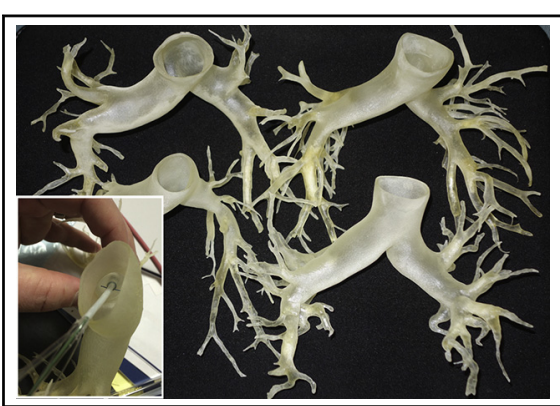

Flexible 3D printed models with inset, showing their use testing a catheter prototype.

\section{Central Message}

Additive 3D printing (rapid prototyping) of specially processed medical images allows the creation of sophisticated pulmonary artery replicas that can be used to facilitate anatomic study, surgical planning, device development, and patient education.

\section{Perspective}

Three-dimensional printing is moving relatively quickly from the domain of manufacturing to medical disciplines and even into the homes of patients and doctors. This protean technology can interest all surgeons by improving their tools or replicating useful anatomic structures for planning operations. In this report, we detail using various software packages to convert CT images into pulmonary arteries to innovate catheter design. This article provides basic information on how to segment imaging data and also tabulates software and hardware resources for the reader. A downloadable STL file of our work is provided for the reader to view or print.

See Editorial Commentary page 980
Supplemental material is available online.

Three-dimensional (3D) printing or additive manufacturing refers to any of the various processes for printing a $3 \mathrm{D}$ object. ${ }^{1}$ Primarily additive processes are used, in which successive layers of material are laid down under computer control. ${ }^{2,3}$ These objects can be of almost any shape or

\footnotetext{
From the Department of Thoracic Surgery, ${ }^{a}$ Roswell Park Cancer Institute, Buffalo, NY; Department of Biomedical Engineering, ${ }^{b}$ Toshiba Stroke and Vascular Research Center, State University of New York at Buffalo, Buffalo, NY; and Engineering and Design, ${ }^{\mathrm{c}}$ Incodema 3D LLC, East Syracuse, NY.

Institutional funds were used for onsite printing of 1 prototype and for the procurement of software packages. Printing services for 9 of the described models were funded by an unrestricted grant from Incodema3D, which employs D.S.

S.K. conducted image translation and 3D process engineering yielding final STL files, image creation, and manuscript preparation. C.I. conducted prototype printing using a university printer and provided manuscript preparation. D.S. conducted oversight of industry prototype printing and made contributions to the manuscript
}

geometry, and are produced from a 3D model or other electronic data source. A 3D printer is a type of industrial robot. ${ }^{1}$ Additive manufacturing technology requires digitized representation of geometrical data, which comes in stereolithographic (STL) or in additive manufacturing file formats.

This technology enables building accurate patient-specific $3 \mathrm{D}$ printed anatomic models that can be used for new surgical instrument development, ${ }^{4}$ physical measurements, diagnosis, surgical planning, and presentation to patients. $^{5-8}$ Such

limited to Table 2 and details of the industry manufacturing process. T.D. is the corresponding author, provided postprinting model analysis and data collection, study conceptualization and design, and manuscript preparation.

Received for publication Aug 31, 2014; revisions received Nov 29, 2014; accepted for publication Dec 31, 2014; available ahead of print Feb 7, 2015.

Address for reprints: Todd L. Demmy, MD, Department of Thoracic Surgery, Roswell Park Cancer Institute, Buffalo, NY 14263 (E-mail: Todd.Demmy@roswellpark. org).

$0022-5223 / \$ 36.00$

Copyright (C) 2015 by The American Association for Thoracic Surgery http://dx.doi.org/10.1016/j.jtcvs.2014.12.059 


\section{Abbreviations and Acronyms \\ 3D $=$ three-dimensional \\ DICOM $=$ Digital Imaging and Communications in Medicine \\ PA = pulmonary artery \\ STL $=$ stereolithographic}

models are useful for educational purposes and physiologic simulations in resident physician training because they increase 3D perception and add tactile feedback to the trainee. In addition, these printers can be used for custom implantable prostheses and are useful for test and validation of newly developed surgical instruments without risk to patients. Disadvantages of this technology are its high relative cost, limited availability of medical-grade biomaterials, and the complexity of translating patient anatomic data to the computer for rendering.

We explored and documented our experience with what we found as the available tools for this rapidly evolving technology with the aim of describing its possible use in thoracic surgical patient care and research. Because of an active research project on regional lung chemotherapy at our institution, human pulmonary arteries (PAs) were chosen for this rapid prototyping project.

\section{MATERIALS AND METHODS \\ Software and Hardware}

Our method of processing computed tomography (CT) scans used 2 commercial software packages: Amira 5.5 (FEI Visualization Sciences Group, Burlington, Mass) and the evaluation version of Vitrea 3D version 6.5.1 (Vital Images, Inc, Toshiba Medical Systems, Minnetonka, Minn). At the time of this project's fulfillment, the combination of these 2 software platforms allowed accurate and efficient PA reconstruction and sufficient preparation of reconstructed models for 3D rapid prototyping. A number of other packages are available (Table 1) and we trialed some of them but we found the above to be the most useful. It should be noted that a variety of radiologic software packages will allow viewing and manipulation of 3D reconstructions, but most do not allow for generation of a file for 3D printing.

The first model was printed on PolyJet Eden 260 V 3D printer (Stratasys, Inc, Eden Prairie, Minn). The printer was chosen because of its fine details, complex geometries, and very thin walls due to ultrafine $16-\mu \mathrm{m}$ layers printing capability. For rigid materials, the accuracy in each printed plane is between 20 and $85 \mu \mathrm{m}$ for features smaller than $50 \mathrm{~mm}$; and up to $200 \mu \mathrm{m}$ for full model size. The net printing area is $255 \times 252 \times 200 \mathrm{~mm}$. For soft materials, the layer resolution is about $32 \mu \mathrm{m}$ and up to $200 \mu \mathrm{m}$ in-plane accuracy. It should be noted that there are now a multitude of $3 \mathrm{D}$ printers at a variety of price points (Table 2). In general, these printers are much more expensive if they are capable of using a variety of printing resins or other materials. For this application, the ability to print a soft material with high tolerances required a relatively expensive device. The models printed at Incodema3D were produced on the Objet500 Connex printer (Stratasys, Inc). The Connex offers the ability to print with dual materials to provide a wide range of soft, rubber-like models.

\section{Process of Preparation}

Ten normal, motion-free (ie, no blurring and streaking) de-identified CT angiograms performed that excluded the diagnosis of pulmonary embolism were supplied by a radiologist at a comprehensive cancer center with no affiliation with this research endeavor. No clinical information about the patients was available to the investigators; however, it was assumed that there probably was little bias selecting the cases from a general pool of patients at a cancer center. Based on institutional policy, biologic or imaging data obtained in this way are exempt from special institutional review board oversight or review. Ten anonymized Digital Imaging and Communications in Medicine (DICOM) formatted files were numbered Ptn_01 to Ptn_10 before data manipulation began.

The process of anatomic model preparation, specifically of the PA, for $3 \mathrm{D}$ printing requires a few substantial steps: data acquisition from the patient's CT digital data; 3D visualization and segmentation; surface rendering and creating a 3D polygon mesh; geometrical surface preparation, including simplification, refinement, and geometry fixing; and hollowing of an existing volume to "thicken" the walls.

Data acquisition. Three sets of data for each patient were selected for visualization and reconstruction-1 contrast CT set at $0.625 \mathrm{~mm}$ $(512 \times 512)$ resolution, $1 \mathrm{CT}$ set at $1 \mathrm{~mm}(512 \times 512)$ and $1 \mathrm{CT}$ set at 2 $\mathrm{mm}$ slice thickness on a GE Optima CT 660 (GE Medical Systems, GE Healthcare, Milwaukee, Wis).

3D visualization and segmentation. The commercial software platforms Amira 5.5 and Vitrea 6.5 were used in conjunction for 3D visualization and data processing. In our findings, the most efficient way for the PA segmentation in Amira 5.5 is connecting the threshold segmentation module with a set of tools such as Blow Tool, Magic Wand, and Threshold Tool. Within the algorithm provided by this module, all gray-value voxels with a defined range of Hounsfield units within the region of interest are selected and directly connected to a predefined voxel.

Because of the high variability of curvature and embedding in complex anatomic scenes with other vessels interference, PA segmentation with Amira tools requires a clear understanding of a patient's anatomy, which takes 4 to 8 hours of time for an experienced operator.

Vitrea 6.5 was then used for additional refinement of the model, especially its most important key feature: the embedded predefined presets for certain types of data and diagnostic questions. Presets were chosen based on the DICOM tags that describe the data sets. ${ }^{9}$ This enabled quick access to the specific anatomic structures such as vessels and automatically segmented, tracked, and labeled them. The model was then exported as STL, also known as a standard tessellation language file. However, at the time of this research, Vitrea 6.5 could not provide surface editing and fixing abilities for the STL files it generated. Therefore, Vitrea 6.5 scaffold models were imported back to Amira 5.5 as STL files.

Surface rendering. Once both the scaffold model and the same DICOM dataset used to create it were loaded in Amira, the noise reduction nonlocal means filter was applied on the data set. Using the ImageCrop editor tool, the region of interest was selected and processed as the isosurface, a closed surface that separates "outside" from "inside." The boundary between "outside" and "inside" is the isosurface.

Next, the Amira ExtractSurface module was attached to the reconstructed isosurface. For easy recognition and volume editing, we selected a dark blue on the Vitrea model, and on Amira's isosurface we used a yellow color. We found that all 10 reconstructed by Vitrea and imported into Amira environment models did not require an additional transformation, reposition, and alignment in Amira, because Vitrea's model exactly overlaps the PA isosurface reconstructed in Amira (Figure 1).

Amira's VolumeEdit module removes noise and/or undesired objects in a 3D image before applying isosurfaces, volume rendering, or other image segmentation. We used this module for removing undesired objects around the PA such as bones, heart, aortic arch, trachea, and pulmonary veins.

The threshold value for isosurface computation was 80 to 120, depending on the ratio between noises to the level of details for every particular DICOM data set. Because the VolumeEdit module does not display any geometry in the viewer by default, we attached VolumeEdit module via the IsoSurface module to the ExtractSurface module. The ExtractSurface 
TABLE 1. Software packages

\begin{tabular}{|c|c|c|c|}
\hline Software package & Cost & Advantages & Disadvantages \\
\hline Amira 5.5 & $\sim \$ 10 \mathrm{~K}$ Depending on modules & Variety of surface editors & Non-fully automated segmentation \\
\hline Vitrea 6.5 & Evaluation version (price unavailable) & Fully automated vessels segmentation & Lack of surface editing and fixing \\
\hline 3D Doctor & $\$ 2400$ & Ease of use & Lack of surface editing and errors fixi \\
\hline Osirix MD & $\$ 699$ & Ease of use & $\begin{array}{l}\text { No surface editing and errors fix. } \\
\text { Requires Mac OS X }\end{array}$ \\
\hline Unic3D & $\$ 500$ & $\begin{array}{l}\text { Fast volume rendering and polygonal } \\
\text { surface reconstruction }\end{array}$ & $\begin{array}{l}\text { Nonintuitive interface and no tool for } \\
\text { surface editing }\end{array}$ \\
\hline 3D Slicer* & Free, open-source & $\begin{array}{l}\text { Automatic image segmentation, } \\
\text { interactive visualization of polygonal } \\
\text { meshes }\end{array}$ & $\begin{array}{l}\text { Requires ad hoc setup for pulmonary } \\
\text { artery reconstruction. Lack of } \\
\text { surface errors fix }\end{array}$ \\
\hline $\begin{array}{l}\text { The Medical Imaging } \\
\text { Interaction Toolkit* }\end{array}$ & Open-source under BSD-style license & $\begin{array}{l}\text { Contains isosurface module for creating } \\
\text { surfaces }\end{array}$ & $\begin{array}{l}\text { Requires ad hoc setup for pulmonary } \\
\text { artery reconstruction }\end{array}$ \\
\hline OsiriX* & Open-source & $\begin{array}{l}\text { Medical imaging and processing with } \\
\text { support of plug-in architecture }\end{array}$ & $\begin{array}{l}\text { Requires Mac OS X. } \\
\text { No surface editing and errors fix }\end{array}$ \\
\hline
\end{tabular}

BSD, Berkeley Software Distribution; $O S$, operating system. *Free and open-source.

module computes a triangular approximation of the surface and visualizes a resulting triangular surface. Figure 2 presents the triangulated PA for patient 2, which contains 69,989 vertices and 139,664 triangles. To a point, the high number of triangles translates into a smoother-appearing surface in the same way that more pixels creates a sharper 2-dimensional photograph. However, too many triangles is bad because of computational limitations and the difficulty connecting all their edges.

Geometrical surface preparation: Simplification, refinement, and geometry fixing. To reduce the number of triangles and to improve the quality of the surface, Amira provides 2 editors: the Simplifier and the Surface Editor. According to Amira's user's guide the surface simplification is done by means of an edge collapsing algorithm. Edges of the original surface are successively reduced to points. The shape of the original surface is preserved by minimizing a certain error criterion. Special care is taken to prevent the triangles of the simplified surface from intersecting each other. However, in some cases intersections can still occur. Therefore, the resulting surface should be checked for intersections using the Surface Editor with the test modules like intersection, orientation, tetra quality, and nonmanifold test. The default value for the Simplifier, suggested by Amira, is 18,000 triangles. In most of our cases we found that using this number reduced the level of detail and removed parts of significant branches. To preserve parts of such branches in reconstructed models we increased the simplification number from 30,000 to 36,000 , which allows simplifying the mesh, preserving the level of detail, and keeping all significant branches of the reconstructed artery intact.

All currently available 3D printers accept STL format files and require a manifold 3D surface topology, which is, basically, a surface that completely encloses a volume. Based on its nature the STL file format has 2 significant problems: it can't detect or fix errors (especially nonmanifold topology and unintended holes) in the part to be built, and it lacks the ability to present surface texturing of the printed models. In our case the second issue was not important, because the models didn't require surface texturing. Amira's Surface Editor recognizes nonmanifold topology and provides a simple

TABLE 2. Plastic and rubber-like additive manufacturing printers and materials

\begin{tabular}{|c|c|c|c|c|c|}
\hline Type/target & Price range & Target applications & Process & Notes & Printer examples \\
\hline $\begin{array}{l}\text { Designers } \\
\text { Conceptual modeling } \\
\text { Professionals } \\
\text { High-end consumers }\end{array}$ & $\$ 200$ & $\begin{array}{l}\text { Design Concept, } \\
\text { Proof of shape }\end{array}$ & $\begin{array}{l}\text { Free-form fabrication, } \\
\text { Extruded filament, } \\
\text { Direct light processing, } \\
\text { UV-cured photopolymer, } \\
\text { PolyJet (Jetting) }\end{array}$ & $\begin{array}{l}\text { Resolution range, } \\
\text { acceptable to good } \\
\text { Multiple colors } \\
\text { Limited dual materials } \\
\text { Moderate print speeds } \\
\text { Range of materials, } \\
\text { typically rigid }\end{array}$ & $\begin{array}{l}\text { 3DLPrinter (Robot Factory) } \\
\text { Mojo, Objet } 24 \text { (Stratasys); } \\
\text { MarkForged (MarkForged); } \\
\text { ProJet series (3D Systems); } \\
\text { Perfactory Micro } \\
\text { (EnvisionTEC) }\end{array}$ \\
\hline $\begin{array}{l}\text { Design tools } \\
\text { Commercial } \\
\text { Professional }\end{array}$ & $\$ 20,000-\$ 200,000$ & $\begin{array}{l}\text { Design verification, } \\
\text { Fit and function, } \\
\text { Appearance models }\end{array}$ & $\begin{array}{l}\text { Fused deposition } \\
\text { modeling, } \\
\text { PolyJet (Jetting), } \\
\text { UV-cured photopolymer, } \\
\text { Selective laser sintering }\end{array}$ & $\begin{array}{l}\text { Multiple color offerings } \\
\text { Production plastics } \\
\text { Production-like plastics } \\
\text { Wax } \\
\text { Investment casting materials } \\
\text { Rubber-like materials } \\
\text { Limited dual materials }\end{array}$ & $\begin{array}{l}\text { 3D Systems (multiple } \\
\text { ProJet models); } \\
\text { Stratasys (Objet and } \\
\text { Fortus series); } \\
\text { Piecemaker (BigRep ONE) }\end{array}$ \\
\hline $\begin{array}{l}\text { Commercial } \\
\text { Professional } \\
\text { Production } \\
\text { Patterns for tooling }\end{array}$ & $\$ 150,000-\$ 900,000$ & $\begin{array}{l}\text { Accurate models used } \\
\text { as patterns, } \\
\text { Production parts, } \\
\text { Fast, accurate design } \\
\text { verification, } \\
\text { Dual materials, } \\
\text { Dental application }\end{array}$ & $\begin{array}{l}\text { Fused deposition } \\
\quad \text { modeling } \\
\text { PolyJet (Jetting) } \\
\text { UV-cured photopolymer } \\
\text { Selective laser sintering }\end{array}$ & $\begin{array}{l}\text { Production plastics, } \\
\quad \text { production-like plastics } \\
\text { Wax } \\
\text { Investment casting materials } \\
\text { Rubber-like materials } \\
\text { High-end costs } \\
\text { High-level accuracy }\end{array}$ & $\begin{array}{l}\text { Fortus 400, Fortus } 900 \\
\text { Object500 Connex, } \\
\text { Object500 Connex } \\
\text { iPro Series, ProX 950, } \\
\quad \text { Projet } 7000 \text { HD } \\
\text { sPro Series, } \\
\text { Lumex Avance-25 } \\
\text { VX } 1000\end{array}$ \\
\hline
\end{tabular}

UV, Ultraviolet. 

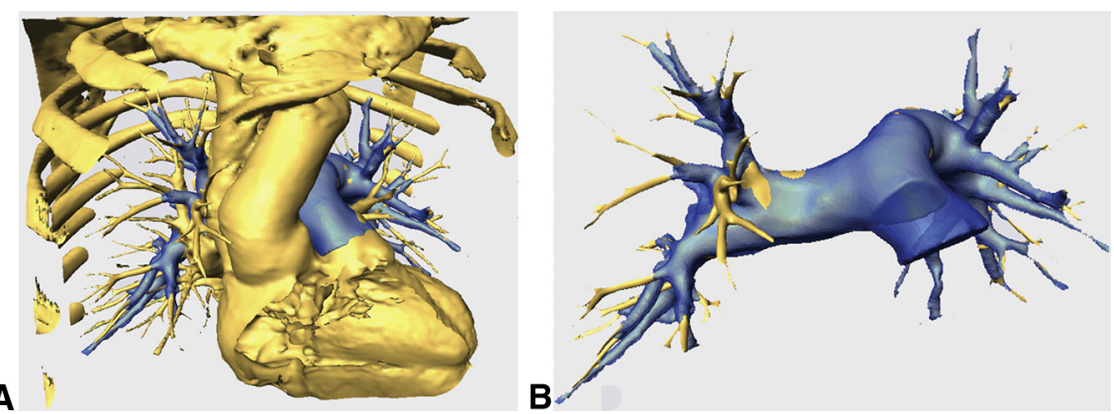

FIGURE 1. A, Isosurface of the region of interest using Amira software (FEI Visualization Sciences Group, Burlington, Mass) with ImageCrop editor and noise reduction filter applied on the axial Digital Imaging and Communications in Medicine stack. Colorized surface rendering of the pulmonary artery as a scaffold model in Amira using Vitrea software (Vital Images, Inc, Toshiba Medical Systems, Minnetonka, Minn). B, Volume "cleaned" after applying the VolumeEdit module in Amira. The blue color represents Vitrea's scaffold model of the rendered pulmonary artery.

interface to manually fix nonmanifold geometry. However, if the reconstructed mesh contains more than 2 nonmanifold topologies, the fixing process in Amira can be time-consuming. To automate the fixing process we used the free software package Meshmixer 0.8 (Autodesk Inc, San Rafael, Calif). Meshmixer allows fully automatic nonmanifold topology repair (using the autorepair tool) and once the geometry was free of errors caused by nonmanifold topology, the cutting plane was utilized manually. The cutting plane was placed midway between the main PA bifurcation and its root to facilitate orientation and introduction of catheters after printing. This step is necessary to add a wall to the model during the extrusion process. With the Meshmixer extrusion utility the walls were extruded in a direction normal to each triangle surface. In a PA model normal extrusion can induce intersection mesh errors, which usually appear at the end of the vessel (Figure 3). To fix these errors Meshmixer provides an interactive tool for local remeshing and reducing the number of mesh triangles. Incodema3D verified the STL data sets using Magics software, version 18 (Materialise, Plymouth, Mich). The data tools from Magics perform final verification of the data sets and ensures the printed models will be identical to the data sets.

Test printing of PAs. After fixing all errors the reconstructed PA model was sent to the PolyJet Eden $260 \mathrm{~V}$ 3D printer Objet500 Connex printer with $1 \mathrm{~mm}$ wall thickness. For the 3D printing we used a rubberlike material referred as TangoPlus; the chemical composition is described in the material safety data sheet shown in Table 3. The material is elastic and semitransparent and behaves as polyurethane. The mechanical properties of the materials are in Table 3, as well.

After printing, the support material was removed using a water jet. A $5 \mathrm{~mm}$ tube connected to a power washer was used to remove the material inside the

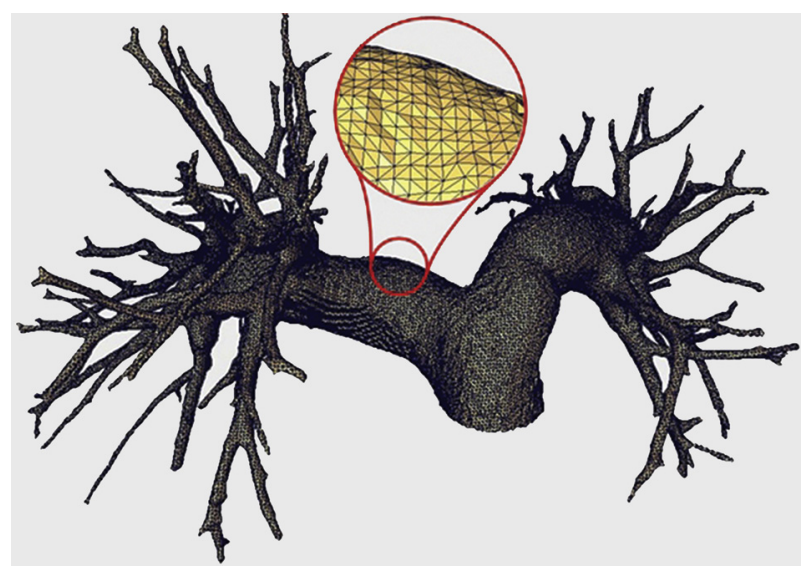

FIGURE 2. Extracted and rendered triangular surface of the pulmonary artery before applying the Simplifier Editor. Highlighted area zoomed $\times 20$. large vessels. The tube connected to the power washer was inadequate for small vessels $(<2 \mathrm{~mm})$ or very tortuous regions. To clean such areas, we used various catheters between $4 \mathrm{~F}$ and $7 \mathrm{~F}$, connected directly to a water faucet. Even in these conditions some material was hard to remove, so in a third step, we soaked the samples in sodium hydroxide solution for 24 hours and repeated the cleaning using a small-diameter catheter. In a final step, to remove the small particles of support material, we connected the phantom to a peristaltic pump (Masterflex L/S Cole Parmer, Vernon Hills, Ill) and ran it at high speed for approximately 1 hour, using the same sodium hydroxide solution.

Once produced, the 10 labeled arteries underwent measurement with a standard flexible metric ruler. Also a flexible catheter was placed within the model lumen and used to study optimal orientation of potential balloon catheters and guidewire lumens. The model was flexed as necessary to determine the optimal catheter course and most direct measurements.

Prototype validation. To determine model validity, measured dimensions were compared with those from the Amira program. Amira

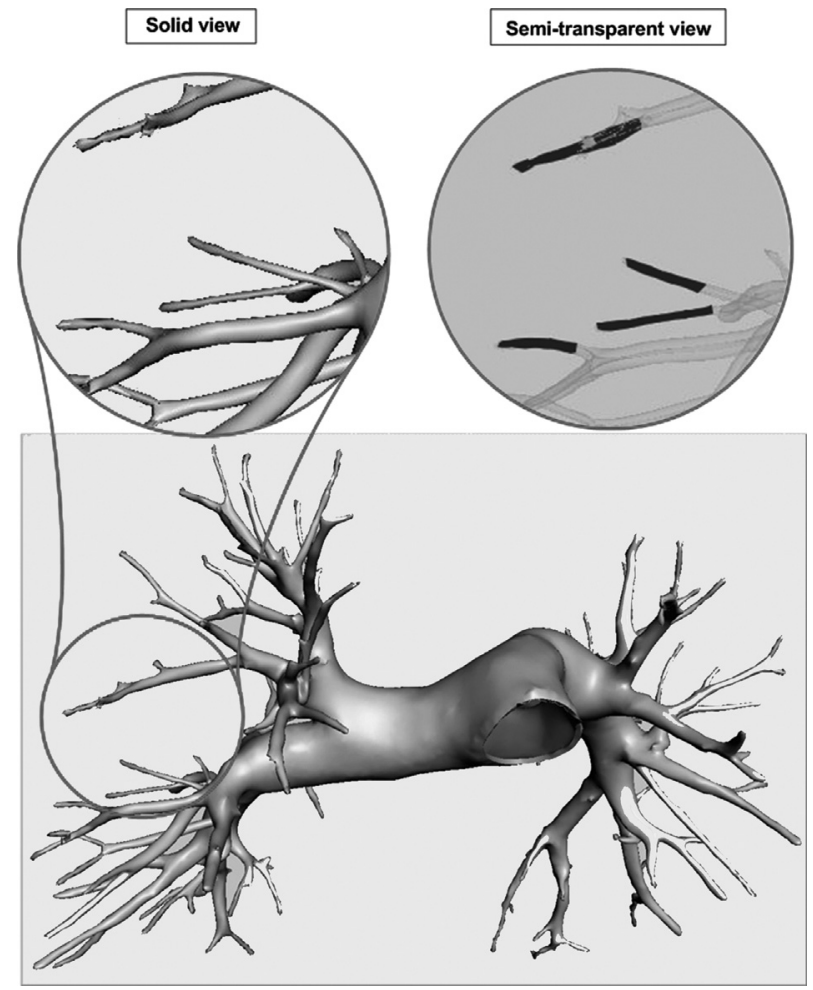

FIGURE 3. Errors on the ends of vessels after walls extrusion. 
TABLE 3. Characteristics of 3-dimensional printing materials

\begin{tabular}{|c|c|c|c|}
\hline & \multicolumn{2}{|c|}{ TangoPlus (Soft material) } & SUP705 (Support material \\
\hline \multirow[t]{5}{*}{ Chemical composition } & \multicolumn{2}{|c|}{ Urethane acrylate oligomer } & 1,2-Propylene glycol \\
\hline & \multicolumn{2}{|c|}{ Methacrylate oligomer } & Polyethylene glycol \\
\hline & \multicolumn{2}{|c|}{ Exo-1,7,7-trimethylbicyclo[2.2.1]hept-2-yl acrylate } & Acrylic monomer \\
\hline & \multicolumn{2}{|c|}{ Resin, polyurethane } & Glycerin \\
\hline & \multicolumn{2}{|c|}{ Photoinitiator } & Photoinitiator \\
\hline \multirow[t]{4}{*}{ Mechanical properties } & Tensile strength (psi) & $0.8-1.5$ & \\
\hline & Elongation at break $(\%)$ & $170-220$ & \\
\hline & Compressive set $(\%)$ & $4-5$ & \\
\hline & Tensile tear resistance (Lb/in) & $2-4$ & \\
\hline
\end{tabular}

dimensions were, in turn, compared with the original DICOM images from the CT scan using Food and Drug Administration-approved medical imaging software (OSIRIX; Pixmeo, Inc, Bernex, Switzerland).

\section{RESULTS}

The design process required approximately 1 working day (6-10 hours) for each model (CT image to STL; see Online Data Supplement). Segmenting the PA was the most timeconsuming step (4-8 hours) and varied because of CT image issues (eg, quality, resolution, and slice thickness); vascular anatomy complexity (eg, artery and surrounding veins); and most importantly, operator experience (eg, anatomy learning curve). The export of reconstructed artery surface to STL file was straightforward in both Amira and Vitrea and took only a few minutes. However, model simplification and nonmanifold surface error fixing took up to 1 hour within Amira (single error) or Meshmixer (multiple defects).

The time for each printing step were as follows: STL integrity evaluation with manufacturing software: 4 hours; build material and layout preparation: 1 hour; printing build 1 (first 6 models) and build 2 (remainder): 72 hours; and removing of support material, cleaning, and fixing (20 hours). The models consumed $2930 \mathrm{~g}$ prototype material and $7200 \mathrm{~g}$ support resin.

The first test printed model with $1 \mathrm{~mm}$ wall thickness was flaccid like an empty PA and relatively fragile because the Tango material does not have the same tensile strength as collagen. Accordingly, the wall thickness was increased to
$1.5 \mathrm{~mm}$ and all 10 models were printed successfully without waste. They all had sufficient wall stiffness to just maintain their appearance in a perfused state yet were malleable enough to perform measurements without damage.

Table 4 displays anatomic measurements that could be useful for general PA catheter design. Dimensions were similar enough to formulate a catheter design that would be effective for most patients. There were some differences between right and left anatomy. Most notably, a single dominant truncal artery was consistent on the right as opposed to the left upper lobe that had a range of 1 to 4 proximal branches. Also, a greater distance between the upper and lower branches approached significance on the right; however, this probably was a function of the more expansive proximal branch pattern.

Whereas many of the measurements in Table 4 could have been made with software analysis of the 3D files, some measurements (in particular, measurements $\mathrm{F}$ and $\mathbf{J}$ in Table 4 and Figure 4) were greatly facilitated by bending the model and aligning the physical catheter. These measurements represent distances beyond which a catheter might cause damage (using $5 \mathrm{~mm}$ external PA as the cutpoint).

The physical measurements of the model were accurate for clinical purposes. For instance, Amira measurement right A was $24.3 \pm 2.7 \mathrm{~mm}$ and $\mathrm{B}$ was $25.7 \pm 2.8 \mathrm{~mm}$ compared with the physical measurements in Table 4. Using a clinically acceptable range of 1 to $2 \mathrm{~mm}(5 \%-10 \%)$, the $95 \%$ confidence levels for these 10 models were contained within this range, demonstrating equivalence. Similarly,

TABLE 4. Anatomic measurements for general pulmonary artery catheter design

\begin{tabular}{|c|c|c|c|c|c|}
\hline Measurement & Right mean & Right median (range) & Left mean & Left median (range) & $P$ value \\
\hline A - Diameter proximal main $(\mathrm{mm})$ & $23.6 \pm 3.0$ & $23.5(19.0-29.0)$ & $25.1 \pm 2.9$ & $24.5(22.0-32.0)$ & .272 \\
\hline B - Diameter distal main $(\mathrm{mm})$ & $24.1 \pm 3.3$ & $23.5(20.0-32.0)$ & $25.5 \pm 3.2$ & $25.0(22.0-32.0)$ & .343 \\
\hline $\mathrm{C}$ - Main length $(\mathrm{mm})$ & $27.3 \pm 7.7$ & $25.0(20.0-45.0)$ & $26.0 \pm 8.5$ & $27.5(12.0-40.0)$ & .724 \\
\hline D - Number initial branches & $1.0 \pm 0.0$ & $1.0(1.0-1.0)$ & $2.5 \pm 1.1$ & $2.5(1.0-4.0)$ & .001 \\
\hline E - Diameter largest initial branch $(\mathrm{mm})$ & $13.1 \pm 3.8$ & $11.5(9.0-19.0)$ & $10.8 \pm 3.7$ & $11.5(5.0-18.0)$ & .189 \\
\hline $\begin{array}{l}\text { F - Distance origin initial branch to } 5 \mathrm{~mm} \text { diameter upper } \\
\text { vessel }(\mathrm{mm})\end{array}$ & $40.6 \pm 14.0$ & $39.0(20.0-65.0)$ & $32.5 \pm 12.8$ & $32.5(10.0-50.0)$ & .194 \\
\hline $\mathrm{G}$ - Diameter after initial branch $(\mathrm{mm})$ & $20.9 \pm 2.5$ & $20.5(18.0-25.0)$ & $20.5 \pm 3.0$ & $20.5(15.0-25.0)$ & .748 \\
\hline $\mathrm{H}$ - Diameter before lower lobe branches $(\mathrm{mm})$ & $18.7 \pm 1.6$ & $19.0(15.0-21.0)$ & $17.9 \pm 4.6$ & $19.0(10.0-24.0)$ & .613 \\
\hline I - Distance between upper and lower lobe branches ( $\mathrm{mm})$ & $17.5 \pm 5.6$ & $16.5(10.0-30.0)$ & $13.0 \pm 4.5$ & $11.5(7.0-20.0)$ & .062 \\
\hline $\begin{array}{l}\mathrm{J} \text { - Distance origin initial branch to } 5 \mathrm{~mm} \text { diameter lower } \\
\text { vessel }(\mathrm{mm})\end{array}$ & $101.5 \pm 22.1$ & $100.0(55.0-135.0)$ & $107.0 \pm 23.9$ & $110.0(60.0-150.0)$ & .601 \\
\hline
\end{tabular}




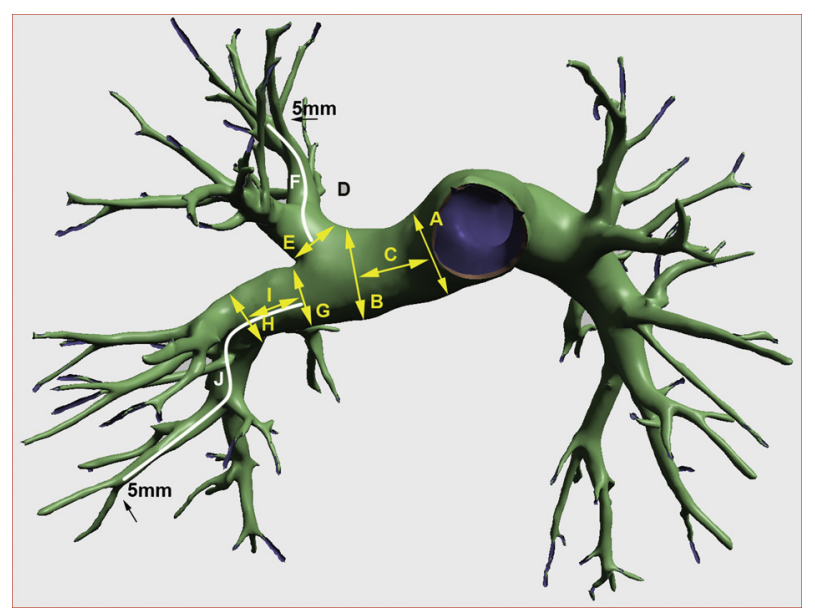

FIGURE 4. Anatomic measurements that could be useful for general pulmonary artery catheter design.

the $95 \%$ confidence intervals comparing Amira with the original DICOM dimensions were equivalent as well.

\section{DISCUSSION}

Our preliminary research shows that it is feasible to create 3D models that might be useful for a variety of surgical needs. Although we used these models for a project to design a catheter for regional lung chemotherapy, the same methodology could be used for a variety of thoracic surgery-related needs (Figure 5). For instance, printing these vessels to create a model for quick reference during a complex video-assisted thoracoscopic surgery lobectomy might be useful. Also, there is a great need to generate lifelike anatomy as part of surgical simulation training. Furthermore, models could be also be useful for patient education in select cases.

In the early 1990s, CT was enhanced by the introduction of helical scanning techniques. This allowed for more precise image segmentation and volume rendering methods that allowed investigators and developers to create

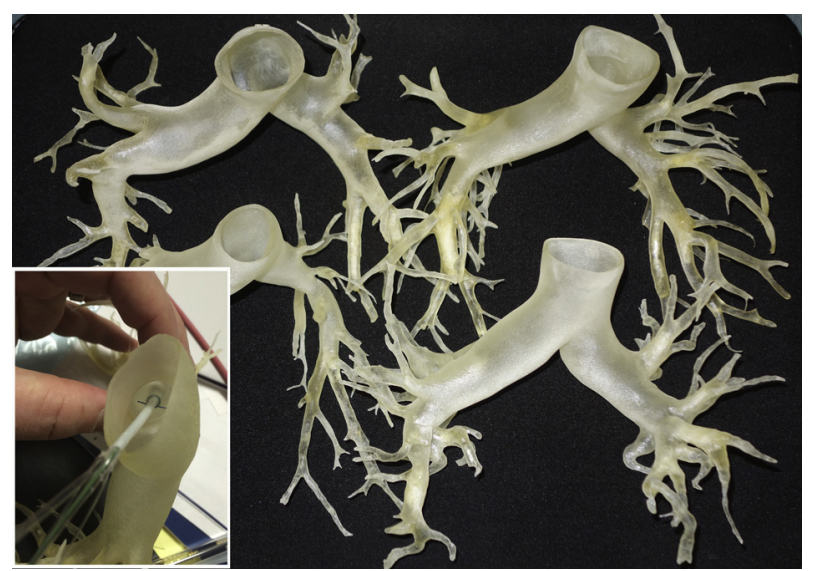

FIGURE 5. Photograph of 4 final models with $1.5 \mathrm{~mm}$ wall thickness printed on 3-dimensional printer. Inset, Close-up view of 1 of the models testing a catheter prototype. polygonal meshes of anatomic structures. These meshes have been employed for virtual reality simulation, surgery preplanning, computer-aided surgery, and 3D printing or, in the words of the manufacturing industry, rapid prototyping. ${ }^{10-12}$ Despite significant advantages of $3 \mathrm{D}$ virtual presentation of anatomy, studies show that anatomy students using plastic models outperformed those who used 3D virtual CT-rendered images. ${ }^{13-15}$

CT data present high bone contrast value in comparison with soft tissue. Thus most medical applications have focused on reconstruction and modeling of bone, ${ }^{16,17}$ spinal structures such as the cervical spine, ${ }^{18}$ models of brain and skull, ${ }^{19,20}$ custom-made implants, and prostheses in oral and craniomaxillofacial surgery. ${ }^{21,22}$ Rapid prototyping of pediatric cardiac models to plan operations probably has been the most frequent use in our specialty. ${ }^{6,23-26}$ Unfortunately, the flexible material used for this model is not appropriate for medical implants such as aerodigestive tract stents.

Before we started this project we hypothesized that there may be difficulty finding a durable hardware solution to produce these flexible models. It turned out that software was the greatest barrier. Polygon meshes rendered as 3D surfaces of anatomic organs can be processed manually, semiautomatically, or fully automatically. Manual rendering is timeintensive because the segmentation-assigning pixels of the image to a particular organ - is processed by an operator. Semiautomatic segmentation allows an operator to segment the region of interest with mouse clicks and algorithms so the path that best fits the edge of the image is shown. A fully automated process of PA reconstruction and STL file preparation is still under active development. ${ }^{7,9,27-29}$ However, even with the advent of the newly developed efficient vessel reconstruction algorithms, the creation of virtual models is relatively timeconsuming and requires expert knowledge of pulmonary vasculature. In addition, this process requires several important postprocessing steps to adapt these models for $3 \mathrm{D}$ printing. ${ }^{30,31}$

Besides the lengthy design time requirements, a limitation of this technology is the cost involved. The whole design process-from the image procurement to complete models printing - cost approximately 10 working days of 1 researcher (S.K.), not counting overhead for software and hardware. The fully loaded printing cost estimate of 1 of these lifesized models is $\$ 700$ of which $15 \%$ is the model resin, $16 \%$ is support resin (necessary for soft productions), $31 \%$ hourly printer charges, and $38 \%$ technician labor costs. Included in this analysis is the assumption that running a $\$ 350,000$ printer depreciated over 5 years at $40 \%$ capacity comes to an hourly overhead charge of $\$ 26$. Software costs per model can be estimated from Table 1 but was less than $\$ 20$ for us because we use this software for many other projects. A commercial vendor will charge 2 to 3 times our overall cost depending on the business model. However, there can be much cheaper options if the user is willing to reduce size, precision, or flexibility in the printed resin. A solid printed 
model can cost around $\$ 100$, but it will lose the ability for catheter insertion as well as flexibility. One limitation of the data supplied in Table 4 is uncertainty whether it fairly represents a broader population of patients. A larger set of validation models or using case selection to seek a more diverse range of human physical characteristics may be needed.

Going forward, this technology competes with virtual education media for health care professionals, trainees, and patients. Complex anatomy can be visualized easily on a scale model at the operating table (rather than manipulating a nonsterile pointing device on a computer). The PAs we printed could be used in a relatively low-cost, lifelike video-assisted thoracoscopic surgery lobectomy trainer. Patients would enjoy a printed memento for education or better long-term documentation of their pathology. The limitations and barriers to implementing 3D printing currently are related to its cost, in particular the time to translate the images to a printing file. However, it is reasonable to expect its use to become rapidly more accessible given the competitive growth of this technology for both commercial and personal applications.

\section{CONCLUSIONS}

Although currently a somewhat tedious process, it is feasible to additively print models of PAs thus replicating these complex anatomic structures to facilitate anatomic study, surgical planning, device development, and patient education. With the advent of specialized software packages allowing automatic segmentation and triangulated surface extraction from $\mathrm{CT} /$ magnetic resonance imaging scans and specialized utilities for geometric surface preparation, this process could be accelerated.

\section{Conflict of Interest Statement}

Institutional funds were used for on-site printing of 1 prototype and procurement of software packages. Printing services for 9 of the described models were funded by an unrestricted grant from Incodema3D, which employs Dan Sammons (https://www.incodema3D.com). All other authors have nothing to disclose with regard to commercial support.

The authors thank Toshiba Medical Systems for the Vitrea station evaluation and the Vitrea developer team members for providing tremendous technical support during the research.

\section{References}

1. Wikipedia.org. 3D printing. Available at: http://en.wikipedia.org/wiki/3D_ printing. Accessed November 22, 2014.

2. 3D Printing.com. What is $3 \mathrm{D}$ printing? Available at: http://3dprinting.com/whatis-3d-printing/. Accessed November 22, 2014

3. Create it REAL. 3D Printing process. Available at: http://www.createitreal.com/ index.php/technology/process. Accessed November 22, 2014.

4. Grimbergen CA, Jaspers JEN, Herber JL, Stassen HG. Development of laparoscopic instruments. Minim Invasive Ther Allied Technol. 2001;10:145-54.

5. Li J. Chapter 9: Design and development of biomedical and surgical instruments in biomedical applications. In: Hudak R, ed. Biomedical Engineering-Technical Applications in Medicine. Rijeka, Croatia: InTech; 2012.

6. Noecker AM, Chen J-F, Zhou Q, White RD, Kopcak MW, Arruda MJ, et al. Development of patient-specific three-dimensional pediatric cardiac models. ASAIO J. 2006;52:349-53.
7. Akiba T, Inagaki $\mathrm{T}$, Nakada $\mathrm{T}$. Three-dimensional printing model of anomalous bronchi before surgery. Ann Thorac Cardiovasc Surg. 2014;20(suppl):659-62.

8. Biglino G, Verschueren P, Zegels R, Taylor AM, Schievano S. Rapid prototyping compliant arterial phantoms for in-vitro studies and device testing. J Cardiovasc Magn Reson. 2013;15:2.

9. Preim B, Oeltze S. 3D visualization of vasculature: an overview. In: Linsen L, Hagen H, Hamann B, eds. Visualization in Medicine and Life Sciences Mathematics and Visualization. New York: Springer; 2008:39-59.

10. Mankovich NJ, Cheeseman AM, Stoker NG. The display of three-dimensional anatomy with stereolithographic models. J Digit Imag. 1990;3:200-3.

11. Hieu LC, Zlatov N, Vander Sloten J, Bohez E, Khanh L, Binh PH, et al. Medical rapid prototyping applications and methods. Assem Autom. 2005;25:284-92.

12. Lantada AD, Morgado PL. Chapter 16: Enhancing product development through CT images, computer-aided design and rapid manufacturing: present capabilities, main applications and challenges. In: Homma N, ed. Theory and Applications of CT Imaging and Analysis. Rijeka, Croatia: InTech; 2011:269-90.

13. Preece D, Williams SB, Lam R, Weller R. Advantages of a physical model over $3 \mathrm{D}$ computer models and textbooks in learning imaging anatomy: let's get physical. Anat Sci Educ. 2013;6:216-24.

14. Rengier F, Mehndiratta A, Tengg-Kobligk H, Zechmann CM, Unterhinninghofen R, Kauczor H-U, et al. 3D printing based on imaging data: review of medical applications. Int J Comput Assist Radiol Surg. 2010;5:335-41.

15. Khot Z, Quinlan K, Norman GR, Wainman B. The relative effectiveness of computer-based and traditional resources for education in anatomy: virtual reality versus reality in anatomy. Anat Sci Educ. 2013;6:211-5.

16. Wang J, Ye M, Liu Z, Wang C. Precision of cortical bone reconstruction based on 3D CT scans. Comput Med Imaging Graph. 2009;33:235-41.

17. Ciocca L, De Crescenzio F, Fantini M, Scotti R. CAD/CAM and rapid prototyped scaffold construction for bone regenerative medicine and surgical transfer of virtual planning: a pilot study. Comput Med Imaging Graph. 2009;33:58-62.

18. Yamazaki M, Akazawa T, Okawa A, Koda M. Usefulness of three-dimensional full-scale modeling of surgery for a giant cell tumor of the cervical spine. Spinal Cord. 2007; 45:250-3.

19. Vannier MW, Marsh JL, Warren JO. Three dimensional CT reconstruction images for craniofacial surgical planning and evaluation. Radiology. 1984;150:179-84.

20. Kelley DJ, Farhoud M, Meyerand ME, Nelson DL, Ramirez LF, Dempsey RJ, et al. Creating physical 3D stereolithograph models of brain and skull. PLoS ONE. 2007;2:e1119.

21. Gateno J, Xia JJ, Teichgraeber JF, Christensen AM, Lemoine JJ, Liebschner MAK, et al. Clinical feasibility of computer-aided surgical simulation (CASS) in the treatment of complex cranio-maxillofacial deformities. $J$ Oral Maxillofac Surg. 2007;65:728-34.

22. Mavili ME, Canter HI, Saglam-Aydinatay B, Kamaci S, Kocadereli I. Use of three-dimensional medical modeling methods for precise planning of orthognathic surgery. Craniofac Surg. 2007;18:740-7.

23. Markert M, Weber S, Lueth TC. A beating heart model 3D printed from specific patient data. Engineering in Medicine and Biology Society 2007. EMBS 2007 29th Annual International Conference of the IEEE; August 22-26, Lyon, France. 2007:4472-75.

24. Jacobs S, Grunert R, Mohr FW, Falk V. 3D-Imaging of cardiac structures using 3D heart models for planning in heart surgery: a preliminary study. Interact Cardiovasc Thorac Surg. 2008;7:6-9.

25. Sodian R, Schmauss D, Markert M, Weber S, Nikolaou K, Haeberle S, et al. Threedimensional printing creates models for surgical planning of aortic valve replacement after previous coronary bypass grafting. Ann Thorac Surg. 2008;85:2105-8.

26. Schmauss D, Gerber N, Sodian R. Three-dimensional printing of models for surgical planning in patients with primary cardiac tumors. J Thorac Cardiovasc Surg. 2013;145:1407-8.

27. McGurk M, Amis AA, Potamianos P, Goodger NM. Rapid prototyping techniques for anatomical modelling in medicine. Ann R Coll Surg Engl. 1997;79:169.

28. Zhang J, He Z, Dehmeshki J, Qanadli SD. Segmentation of pulmonary artery based on ct angiography image. 2010 Chinese Conference on Pattern Recognition; October 21-23, Chongqing, China. 2010:1-5.

29. Hong Q. A survey on the visualization and reconstruction of vasculatures. Available at: http://spie.org/Publications/Proceedings/Paper/10.1117/12.2050062. Accessed November 22, 2014.

30. Ionita CN, Mokin M, Varble N, Bednarek DR, Xiang J, Snyder KV, et al. Challenges and limitations of patient-specific vascular phantom fabrication using 3D Polyjet printing. SPIE Medical Imaging. 2014;9038:90380M.

31. Cloonan AJ, Shahmirzadi D, Li RX, Doyle BJ, Konofagou EE, McGloughlin TM. 3D-printed tissue-mimicking phantoms for medical imaging and computational validation applications. 3D Print Addit Manuf. 2014;1:14-23. 
TABLE E1. Additive manufacturing low-end and metal printers and materials

\begin{tabular}{|c|c|c|c|c|c|c|}
\hline Type & Target & Price range & Target applications & Process & Notes & Printer examples \\
\hline Plastics & $\begin{array}{l}\text { Consumers } \\
\text { Education } \\
\text { Introductory } \\
\text { Do-it-yourself } \\
\quad \text { kits }\end{array}$ & $\$ 250-\$ 5000$ & $\begin{array}{l}\text { Students, } \\
\text { Home use, } \\
\text { Concept models }\end{array}$ & $\begin{array}{l}\text { Free form fabrication, } \\
\text { Extruded filament, } \\
\text { Direct light processing, } \\
\text { UV-cured photopolymer }\end{array}$ & $\begin{array}{l}\text { Intro into 3-dimensional } \\
\text { printing } \\
\text { Resolution range is limited } \\
\text { Multiple colors } \\
\text { Limited material selection }\end{array}$ & $\begin{array}{l}\text { Printrbot, mUVe, DLP } \\
\text { MakerBot, Cube } 3 \\
\text { ProjJet 1200, } \\
\text { B9Creations 3D } \\
\text { Afinia H-Series }\end{array}$ \\
\hline Metal & $\begin{array}{l}\text { Professional } \\
\text { Production } \\
\text { Tooling inserts } \\
\text { Jewelry } \\
\text { Medical } \\
\text { Dental }\end{array}$ & $\begin{array}{l}\$ 300,000- \\
\$ 1,000,000\end{array}$ & $\begin{array}{l}\text { Production parts Relatively } \\
\text { fast, High-level accuracy } \\
\text { Research and development } \\
\text { functional parts in real } \\
\text { metal }\end{array}$ & $\begin{array}{l}\text { Direct metal laser } \\
\quad \text { sintering } \\
\text { Laser melting } \\
\text { LaserCusing } \\
\text { Electron beam melting }\end{array}$ & $\begin{array}{l}\text { A good range of real } \\
\text { metal materials } \\
\text { Aerospace, Transportation, } \\
\text { energy, aviation } \\
\text { Medical/dental implants } \\
\text { Production parts }\end{array}$ & $\begin{array}{l}\text { EOS M290 (DMLS), } \\
\text { AM250 (Renishaw) } \\
\text { ProX } 300 \text { (3D Systems), } \\
\text { M2 Cusing, X Line 1000R } \\
\quad \text { (Concept Lasers) } \\
\text { Arcam Q10, Arcam Q20 }\end{array}$ \\
\hline
\end{tabular}

UV, Ultraviolet. 